\title{
Social Networks Addiction: Could Social Advertising Help?
}

\author{
Maria A. Mitina \\ Volgograd State Technical University, Volgograd, Russia \\ Elena G. Popkova \\ Professor, Doctor of Economics of Volgograd State Technical University, Volgograd, Russia \\ Lilia V. Ermolina \\ Lecturer of the Dept. of Industrial economy, Samara State Technical University, Samara, Russia \\ Irina N. Sherer \\ PhD in social science, Associate professor of the chair of HCM, \\ Volgograd State Socio-Pedagogical University, Volgograd, Russia
}

\section{Doi:10.5901/mjss.2015.v6n3s6p177}

\section{Abstract}

With the development of modern technologies, society continues facing new problems which are reflected in the products of social advertising. One of these problems which draws more and more attention of the society is an issue of social networks addiction. However, the results of the recent research and analysis of advertising content, devoted to the topic, showed that specialists and professionals pay comparatively little attention to this issue, in spite of its popularity and topicality. The conclusions of this work may provide a direction for the further research.

Keywords: social advertising, social networks addiction, social networks functions, virtual communication, Facebook Addiction Disorder.

\section{Introduction}

The $21^{\text {st }}$ century brought global problems which should be solved. Of course, the main topic is solving ecological problems which have a global character. This has brought to life a lot of researches, connected with one topic, in various spheres of science and activities which continue to appear today. Thus, E.G. Popkova, professor and doctor of economics of Volgograd State Technical University produced works devoted to ecological marketing and analysis of economic effectiveness of marketing management at ecologically oriented enterprise.

It would have seemed strange that against the background of these problems which must unite the humanity and in conditions of mass distribution of Internet which advantages expansion and simplification of human communication, modern psychology is faced with the phenomenon of "Ioneliness in a crowd". People, who have hundreds of "friends" in social networks, complain about lack of attention and feeling of desolation.

While psychology is not able to give an answer to the question, what are the consequences of this dependence for the future, social advertising tries to draw attention to growing involvement of people into the virtual reality.

\section{Social Networks: Illusion of Thousand Friends}

Social networks began gaining popularity back in $90-\mathrm{s}$, and went through a glut by now. User pages became an important area for publishing, sharing, and discussing news, having a possibility to influence public opinion. Representatives of retail and service business paid their attention to social networks, using them as trading areas and additional marketing tool, which was possible due to a huge audience. At present, people do not only get acquainted, communicate, look for friends or for love in social networks, but also play games, listen to the music, watch movies, get news, share files, and do a lot of other stuff, which is enabled by constantly expanding functionality.

Universality, easy access, and simplicity of social networks led to the fact that more than $90 \%$ of Russian internet 
users utilize social networks. Approx. 65.9 million people use RuNet (let alone the Internet) every month. According to the Brand Analytics statistics, every day about 30 million new messages (350 posts per second) appear in social networks, and 35 million people leave at least one public message once a month.

According to the report "Mail.Ru Group: Social Networks in Russia", in 2014, top three social networks for Russian, according to monthly attendance, are: "VKontakte" (52.7 million users), "Odnoklassniki" (42.6 million users) and "Moy mir" (30.6 million users). Foreign social networks are represented by 25.4 million users of "Facebook" and 11.6 million users of "Twitter" (see Table 1).

Table 1 - Monthly attendance of social networks

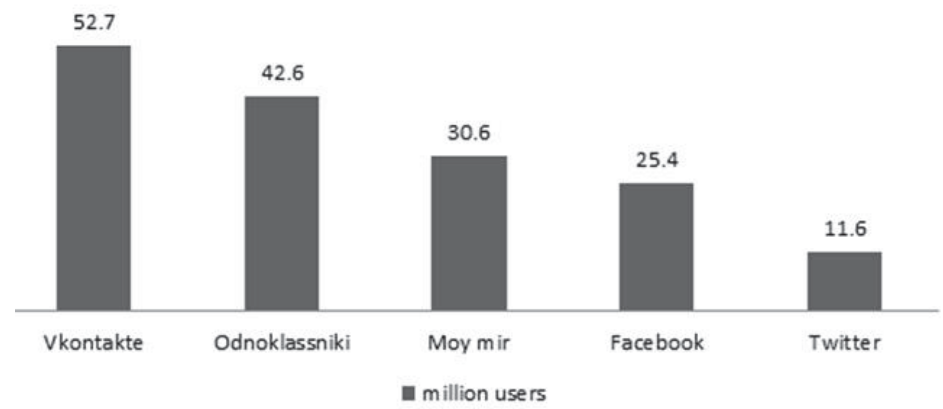

Statistics shows that the share of women among social networks users is higher than that of men - $52 \%$ to $48 \%$, and, according to Mail.Ru Group, the most active users of social networks are young people aged 25-34. They constitute approximately $27 \%$ of RuNet users.

The Brand Analytics Company discerned several general trends of public messages topics, based on the most popular social networks in Russia:

- Users share the news from mass media and discuss them. They spread the news, comment it, and discuss socially important events. The number of these messages depends largely in the informational background. At usual times, such messages constitute about $40 \%$ of the feed, and during the high profile incidents (e.g., opening of the Olympics), the quantity of discussions rises substantially.

- About themselves. What they do, where they are, what they eat, what they think, and what they feel. The number of these messages constitutes about $15-20 \%$ of the feed.

- They create the news themselves. They share information, photos and videos from the scenes - about sport events, exhibitions, festivals, incidents, accidents, etc. This type of messaging is growing due to the wide distribution of mobile devices with internet connection (precisely - popularization of smartphones and tablets), photo cameras and video recorders.

- They discuss products, services, and events. They share consumer experience, impression from movies, and give recommendations to other users.

- They spread entertainment content. This group of messages includes jokes, beautiful pictures, drawings, quotes, etc.

Why are social networks so popular? That might be explained by the following factors:

First, satisfying the requirements for stimulation. A man considers the stimuli, received from other people, to be the most important ones. That is especially important in the teen age, when a teenager subconsciously looks up to respected persons and seeks approval from the persons who are important for him.

A sudden attention from a strange person who has an interest for a web-page of social network user, offers "friendship", or simply is a regular guest on a page, is considered as an important stimulation, and is a substantial factor for ego boost of the user.

Second, satisfying the requirements for events and novelty. Relations which do not have dynamics, development, and new impressions are boring and have a low interest for people, dying with time. A man is not satisfied with good and permanent relations, if they do not bring new events into life.

Social networks allow not only demonstrating our own events, showing them at photos and video, but viewing and discussing the events of the friends-subscribers which are being constantly refreshed, creating the illusion of intension of our own life and satisfying the interest to the lives of others.

Third, satisfying the requirements for accomplishments and recognition. High demands of a man, related to self- 
esteem and self-respect are satisfied by posting messages about private accomplishments and advances (work, financial well-being, wellness, family, etc.) on the social network pages, as well as by viewing and commenting such posts of other users.

Fourth, speed and availability of the pleasure. Subconsciously a person looks for easy ways to get pleasure, often ignoring their bad consequences. We get pleasant emotions and satisfaction when we see a positive comment under our own post. We may stay wide awake if we're subscribed to informational agencies. We don't need to look for something complicated or create anything to attract the minimum attention.

Fifth, ability to switch quickly a role. Creating a page and filling it with data, a user may choose an image to let the others see it. It can be easily changed, deleting the drawbacks and adjusting it to the necessary result, looking experimentally for the most interesting image which corresponds to the existing aims. Having complete anonymity, it's possible to easily be someone else - and then, if necessary, delete the account and start everything again.

\subsection{Positive influence of social networks}

Certainly, communication in social networks in a form of text messages cannot be considered as comprehensive - it is rather quasi-communication, i.e. the pretended one. We suppose that we know our companion well enough, judging by his messages and our own stable opinion and stereotypes regarding him. Usually, it leads to exaggerated expectations from both sides which often do not take the test of reality. Moreover, the effectiveness of such communication and time spending is ambiguous, as a rule.

Speaking of positive sides, it's possible to note that social networks simplified the search for people who are interesting for us, acquaintance and communication, effacing boundaries between people from different cities and countries and expanding communications, allowing easy and simple interacting with those who are far away.

Capabilities of social networks allow users not only to get the news, but also to take part in its creation, organize events, groups, and projects, inviting friends and making new ones, thus developing the ability to realize ideas, create a team, maintain activity in the group with new material and events.

Due to social networks, a person may feel as a part of social group without being obliged to make any efforts. It's enough to simply register in the group or copy the posts which confirm your participation in it.

A huge amount of content which a user fills his page with advantages his self-determination and self-presentation at various levels, from common to value ones. However, a lot of users subconsciously not only try to choose their interests, but also to tell people around them about that.

Publicity is becoming a norm of current life, so such material can tell a lot to an outside observer, providing a glimpse of a page user, narrowing his search for like-minded persons, and giving a possibility of writing a couple of words of greeting or sending a friendship request, hoping for a positive respond without harm to his self-esteem in case of refusal.

Social network is a place with a lot of text and special meaning of words: one should give a smart answer to a comment, show subtly to someone his affection, or demonstrate intellectual superiority - thus, a necessity for developing and improving our own speech appears. A need to express oneself according to the situation, argue in favor of ideas, and write the text of various complexities and for various audiences. Such training can create a foundation for skill to lead discussions, while facing inadequate behavior of an opponent.

In the same way, a form of text messaging supposes having enough time for careful answers, because it's not necessary to answer immediately in social networks, which gives time for evaluation and analysis of the situation and choosing the best strategy of behavior.

Social networks are a rather ironical environment in which there is humor of various categories. Any user sooner or later faces pressing a conflict from an opponent with obvious or hidden rudeness. As a result, social networks teach to be flexible towards other critics, taking it with humor.

Social networks also help to work out a model of communication and determine limits in personal relations. Most of modern teenagers have felt virtual love. At that, some people think that it is important to create a "in love" status and share photos with beloved ones, showing everybody their new relations, and others, having long-time relations, consider their page to be their own area and do not demonstrate the presence of a soul mate.

Therefore, social networks are a fair opportunity for quick search of like-minded persons, sharing information, simplifying the process of communication with people and groups, establishing contacts for realization of creative and professional potential, self-development, and self-presentation. 


\subsection{Negative aspects of social networks}

Unfortunately, positive potential of social networks is, as a rule, poorly used by an average user; the most part of these contacts are sharing insignificant information at the level of interpersonal communication, which brings us to viewing negative moments.

It should be noted that the form of publicity and general availability of private information form a certain psychology of behavior of social networks users. On the one hand, there is a shift of satisfying an interest in events from friends', colleagues', and acquaintances' to obsessive need for constant consuming of information of all changes without a clear goal. On the other hand, transformation of a need for self-expression to a massive and systemless filling of a page with any facts about yourself, without caring for usefulness of this material.

Many people consider a possibility of free publication of personal information to be a huge drawback; they claim that social networks neglect privacy, pass personal data to authorities or secret services, but at the same time they do not heed the fact that most information is published voluntarily, though not always fully consciously.

We fill in a questionnaire and type in our real name, phone number, date of birth, sexual orientation, political views, work and study information, we create a list of best friends and family members - all of that is in the open access, thanks to ourselves. 25 years ago, it was supposed to be confidential information, for the search of which dozens of private detectives were hired - and now it suffices to have a look at a person's page, in order to learn everything about him.

Moreover, we voluntarily and with pleasure tell the world what we were doing last night, where we are going to be next weekend, and what we do at work. Giving no thought to the concequences, we post much more information about ourselves and our relatives, than anyone should ever have learned.

Thus, for example, S. Rambam - a private investigator, delivering the report "Privacy is Dead" at the Hackers On Planet Earth conference, thinks that, "Advertising, targeted to absurdity - that's what it's all done for. It is no Big Brother watching us, guys - these people want to sell you something. It's all because of money. It doesn't have anything to do with a desire to humiliate or destroy you. That's an engine for capitalism, that's it. They want to sell you stuff! They want to know everything about you, in order to do it better".

Due to that constantly refreshing flow of events and news, generated by other users, an illusion of active life and intense communication, filled with new information and impressions, is created. Due to the simplicity of companion search and their quantity, the communication is depreciated, and real contact in life is lost.

A constantly reminding wish to check the page and new messages or get the latest news takes much more time from a user, than he plans to spend. Starting his day from checking his page up, a user may not notice that he has actually spent the whole day, commenting on other pictures, instead of previously planned business or active leisure for his own benefit.

Apart from that, social networks allow manipulating people, implementing in their minds dangerous thoughts, focusing attention, and sharing certain ideas. A pretended anonymity creates an illusion of overindulgence which, in its turn, is a fertile ground for expansion of virtual rudeness. The news, published in social network, in their turn may not be true, but, on the contrary, fake.

Social networks may be a platform for various groups serving someone's interests - e.g., propaganda of radical attitude among youth or creation of political tension, aggravation of interethnic and religious strives. It should be taken into account that material posted by the members of social networks is not always fit for children's comprehension, while there are no age limits for registration.

It also should be noted that maniacal desire to stay informed of all events of friends and demanding password to the social networks page, considered as a symbol of utter trust, often leads to family tragedies and quarrels. According to specialists, during last two years, starting from 2012, about 15\% of marriages in Russia were dissolved due to the persons participating in social networks in the internet. According to the psychotherapist G. Golubev from SaintPetersburg, in the past, specialized dating sites were the reasons for divorces - but now their role is taken by social networks.

"My practice includes a lot of cases when families began splitting up because one of the spouses was actively using social networks," says family psychologist and psychotherapist B. Novoderzhkin. "As a rule, that is tied to failed or continuing affairs back in school. These affairs can appear again after many years.

However, L. Shcheglov, the principal of Institute of psychology and sexology, isn't apt to dramatize: "There always have been situations, when marriages were destroyed because one of the spouses getting back to the love of his youth. However, back in the past, the starting point for that were not social networks in Internet, but accidental meetings or traditional schoolmate anniversaries".

In summary of the above negative features, it should be noted that social networks by themselves do not create 
their drawbacks; generally, negative features are caused by human factors and behavior of a certain individual, which may be shown on the example of the following ambiguity (see Figure 1).

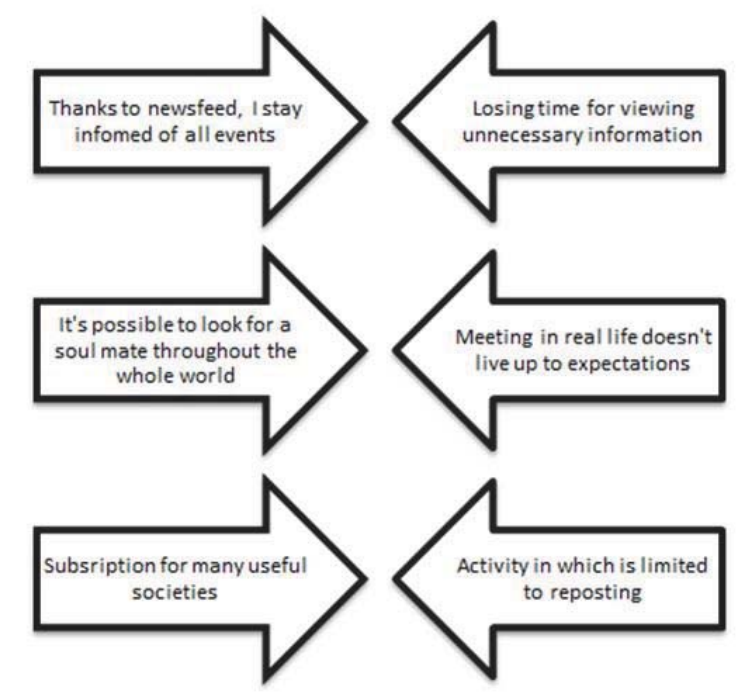

Figure 1 - Ambiguity of activities in social network

\section{Addiction to Social Networks}

While there are arguments regarding pros and cons of social networks, no one has any doubts that there is an addiction to them. According to A. Kibitov, the head of laboratory of molecular genetics of "National scientific center for narcology" of Ministry of Healthcare of the Russian Federation, the mechanism of social networks addiction is similar to the mechanism of addiction to alcohol and drugs; the only difference is that it has non-chemical character. Genetic markers, specific for internet and social network addiction, match with an 80\% agreement with characteristic markers for drinkers and drug-addicts. Non-chemical addictions include, apart from internet addiction and social network, game addiction and obsessive shopping.

Recently, American psychologists presented a new term: FAD or Facebook Addiction Disorder. That is state, determined by the time spent on communication in Facebook - one of the most popular foreign social networks. A person with social network addiction spends a lot of time on it, thus breaking a healthy life balance, which negatively influences a personality.

This disorder is described by six symptoms; they fit to describe an addiction to any social network. Persons with FAD show at least 2 or 3 of following symptoms within 6-8 months:

1. Addiction: spending more and more time on the site, a user comes to a stage when it becomes an obsessive addiction. He feels a constant desire of presence on Facebook, so he could be pleased with life.

2. Symptom of cancelation: it appears when a person loses the opportunity to use Facebook and has to participate in usual everyday life. He experiences the sense of trouble, irritation, depression and worry, and obsessive thoughts about messages that he probably received during the time of his absence.

3. Reduction of normal social activity: a user substantially reduces the time he devoted to personal communication with friends, sports, walks, hobbies and other activities. All free time is devoted to Facebook and spend for many-hour viewing of profiles and photos, often of unknown people.

4. Virtual dates: real dates are substituted by virtual ones. Instead of going to party, movie, or dinner, Facebookaddicts tell their partner that they will be online at the designated time.

5. False friends: 8 out of 10 people, shown on Facebook are completely strange people, whom a user never met in the real life.

6. Complete addiction: any notifications, messages, posts, or requests from users evoke a huge excitement.

In their turn, scientists from American psychiatric association officially recognized that addiction to "selfie" which became popular due to social network Instagram is a psychogenic disorder and named it "selfies". Thus, selfies is determined as obsessive compulsory disorder, characterized with constant desire to take pictures of yourself and post 
them in social networks, compensating for lack of self-respect. The article says that at present, there is no cure for selfies. However, an issue of the character of this interest and its influence on man has been often discussed during recent years.

For example, in March 2014, Mirror published a history of 19-year-old D. Bowman who had been taking pictures of himself 200 times per day and, eventually, had tried to commit a suicide, being unable to do a "perfect selfie". Later he was diagnosed with obsessive compulsory disorder.

\subsection{Social advertising about addiction to social networks.}

Of course, social advertising cannot overlook the issue of growing addiction to social networks. Though terminology of the addiction problem is not yet stable, the quantity of content, reflecting this issue, continues to grow - both in Russia and abroad.

For example, the issue of influence of family on internet-addicted teenagers through a model of interference is discussed in the work of Chinese researchers. They came to the conclusion that collective family interference is more effective for decrease of Internet use and strengthening of family function.

Taiwan doctor of philosophy Zhao-Chiang Wan studied the motives of virtual relations and, as a result of his empirical research, offered nine factors which influence the motives of virtual relations: anonymity, possibility to get to know new people, simple communication, curiosity, emotional support, and social compensation, detachment from real world, and love and sexual partners. In a similar fashion, there was conducted a research devoted to the analysis of behavior, influencing the participation in online games from the point of view of virtual communication.

Within social advertising, there are numerous works devoted to this fact. They are presented by participants of contests and festivals. Thus, at the "Open World" social advertising festival, organized by youth policy department of Krasnodar Krai in 2013, one of the winners of "Social Audio" nominee A. Davidyants told that her audio contained sounds which are known to every internet user - notifications of messages, mouse clicking, etc. Alexandra wanted to show that a modern man lacked real communication and sounds of surrounding life.

Numerous video graphic materials are, as a rule, a comparison of real and virtual communication, trying to remind all social network users, what they lose with complete addiction and isolation from surrounding world.

Thus, for example, a video made by professional Thai advertisers draws people's attention to what they see every day. The video shows how people, being busy in mobile internet, do not notice and ignore the beloved ones that surround them and how life becomes full of bright colors, once they put a smartphone aside.

A video of students of the group of media communication of Vasily Karazin Kharkiv National University shows in a humorous way a short story of two young people who are haunted by social networks.

\section{Conclusion}

It should be noted that a lot of works are amateur, being created by young people who are considered to be the most active part of social network users. It proves the topicality and actuality of the problem once more, together with lack of indifference to the issue.

It should be noted that the increase of the share of professionally and creatively made social advertising is needed; it should be devoted to the addiction to social networks and should be placed on the city streets together with advertisements on other topics.

\section{References:}

Aldridg, G., Harden, K. (2014). Selfie addict took two hundred a day - and tried to kill himself when he couldn't take perfect photo. Retrieved from http://www.mirror.co.uk/news/real-life-stories/selfie-addict-took-two-hundred-3273819

Lin, H.-Y., Chiang, C.-H. (2013). Analyzing behaviors influencing the adoption of online games from the perspective of virtual contact. Social Behavior and Personality: An international journal, 41(1), 113-122.

Mail.Ru Group. (2014). Social networks in Russia 2014. Retrieved from https://corp.mail.ru/media/files/issledovanie-auditorij-sotcialnykhsetej.pdf

Sturt, D., Nordstrom, T. (2014). The 'selfie': mental disorder or insight to getting better results? Retrieved from http://www.forbes.com/ sites/davidsturt/2014/04/29/the-selfie-mental-disorder-or-insight-to-getting-better-results/

Summers, A. (2011). Facebook addiction disorder - The 6 symptoms of F.A.D. Retrieved from http://socialtimes.com/facebookaddiction-disorder-the-6-symptoms-of-f-a-d_b60403

Wang, C.-C., Chang, Y.-T. (2010). Cyber relationship motives: Scale development and validation. Social Behavior and Personality: An 
international journal, 38(3), 289-300.

Zhong, X., Zu, S., Sha, S. (2011). The effect of a family-based intervention model on Internet-addicted Chinese adolescents. Social Behavior and Personality: An international journal, 39(8), 1021-1034.

Voronovich, A. (2013). Youth found a way to deal with violence, bad habits, and Internet addiction. Retrieved from http://www.vkpress. ru/vkinfo/molodezh-nashla-sposob-razobratsya-s-nasiliem-vrednymi-privychkami-i-internet-zavisimostyu/?id=64360

Kostyukovskiy, A. (2008). Social networks to be blamed for divorces. Retrieved from http://www.dp.ru/a/2008/04/03/Vinovati_li_v_ razvodah_sol

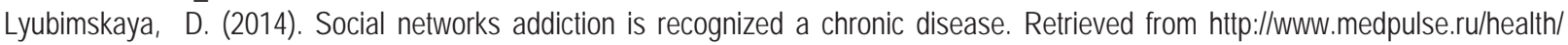
prophylaxis/psychotherapy/15745.html

Popkova, E.G., Dubova, Y.I., Yakovleva, E.A., Azarova, N.A., Titova, E.V. (2014). Role of ecological marketing in formation and development of ecological cluster. Asian Social Science, 10(23), 1-8.

Popkova, E.G., Shakhovskaya, L.S., Volosatova, U.A., Ostrovskaya, V.N., Ponomareva, L.V. (2014). Economic efficiency management of the marketing activity of an ecology-oriented company. Life Science Journal, 11(12), 180-184.

Rambam S. (2012). Privacy is Dead. Retrieved from http://www.warandpeace.ru/ru/analysis/view/70845/ 
